\title{
Advances in the Microbial Synthesis of 5-Hydroxytryptophan
}

\author{
Xin-Xin Liu ${ }^{1}$, Bin Zhang ${ }^{2}$ and Lian-Zhong Ai ${ }^{\text {* }}$ \\ ${ }^{1}$ Shanghai Engineering Research Center of Food Microbiology, School of Medical Instrument and Food Engineering, \\ University of Shanghai for Science and Technology, Shanghai, China, ${ }^{2}$ College of Bioscience and Bioengineering, Jiangxi \\ Agricultural University, Nanchang, China
}

5-Hydroxytryptophan (5-HTP) plays an important role in the regulation of emotion, behavior, sleep, pain, body temperature, and other physiological functions. It is used in the treatment of depression, insomnia, migraine, and other diseases. Due to a lack of effective biosynthesis methods, 5-HTP is mainly obtained by natural extraction, which has been unable to meet the needs of the market. Through the directed evolution of enzymes and the introduction of substrate supply pathways, 5-HTP biosynthesis and yield increase have been realized. This review provides examples that illustrate the production mode of 5-HTP and the latest progress in microbial synthesis.

Keywords: 5-hydroxytryptophan, tryptophan hydroxylase, L-trp, biosynthesis, tetrahydrobiopterin

\section{OPEN ACCESS}

Edited by:

Yi-Rui Wu,

Shantou University, China

Reviewed by:

Zhongyang Qiu,

Huaiyin Normal University, China

K. Madhavan Nampoothiri,

National Institute for Interdisciplinary

Science and Technology (CSIR), India

${ }^{*}$ Correspondence:

Lian-Zhong Ai

ailianzhong1@126.com

Specialty section:

This article was submitted to Industrial Biotechnology, a section of the journal Frontiers in Bioengineering and Biotechnology

Received: 31 October 2020 Accepted: 04 January 2021

Published: 03 February 2021

Citation:

Liu X-X, Zhang B and Ai L-Z (2021) Advances in the Microbial Synthesis of 5-Hydroxytryptophan

Front. Bioeng. Biotechnol. 9:624503.

doi: 10.3389/fbioe.2021.624503

\section{INTRODUCTION}

5-Hydroxytryptophan (5-HTP) is a natural amino acid (AA) that does not participate in protein synthesis. It is derived from tryptophan (trp), and the hydrogen atoms at the 5 -position on the benzene ring of trp are replaced by hydroxyl groups. 5-HTP appears as a fine white powder that is insoluble in water, but is soluble in alcohol. In mammals, 5-HTP is the precursor of the neurotransmitter serotonin and the amine hormone melatonin. It has been successfully used in the treatment of depression, insomnia, migraines, and other diseases due to its regulatory effects on sleep, pain, appetite, and other physiological functions (Figure 1) (Birdsall, 1998). 5-HTP is widely used for psychotropic drugs and weight loss in developed countries. Health-care drugs with 5-HTP as the main ingredient are used in 20 countries. To date, 44 preparation types have been developed worldwide mainly in the form of capsules with $100-150 \mathrm{mg}$ content, as well as in the form of tablets, powders, and sustained-release agents (JunDe et al., 2014). According to the 2014 Thomson Reuters market research report, the annual global sales of 5-HTP were $\$ 7.5$ million, an increase of $50 \%$ over the same period the previous year, with an annual consumption of 1.6 tons.

At present, 5-HTP is mainly extracted from natural products, specifically from the seeds of the African plant Griffonia Simplicifolia, but this method of extraction is unable to meet the market demand due to high cost and a lack of raw materials. Chemical synthesis does not depend on natural products. However, it is not currently possible to synthesize 5-HTP economically and effectively due to the tedious steps involved and harsh conditions required. With the development of biotechnology in bioinformatics, genetics, metabolic engineering, biochemistry, protein engineering, and so on, new strategies are available for the use of microorganisms to synthesize 5-HTP. The production of 5-HTP by the microbial method has the advantages of short production cycle, continuous production and mild reaction conditions. Among the organisms used for this method, Escherichia coli is a model strain of prokaryotes with clear genetic information and well-established fermentation conditions, making it particularly well-suited for use as a host cell for the study of 5-HTP biosynthesis. 


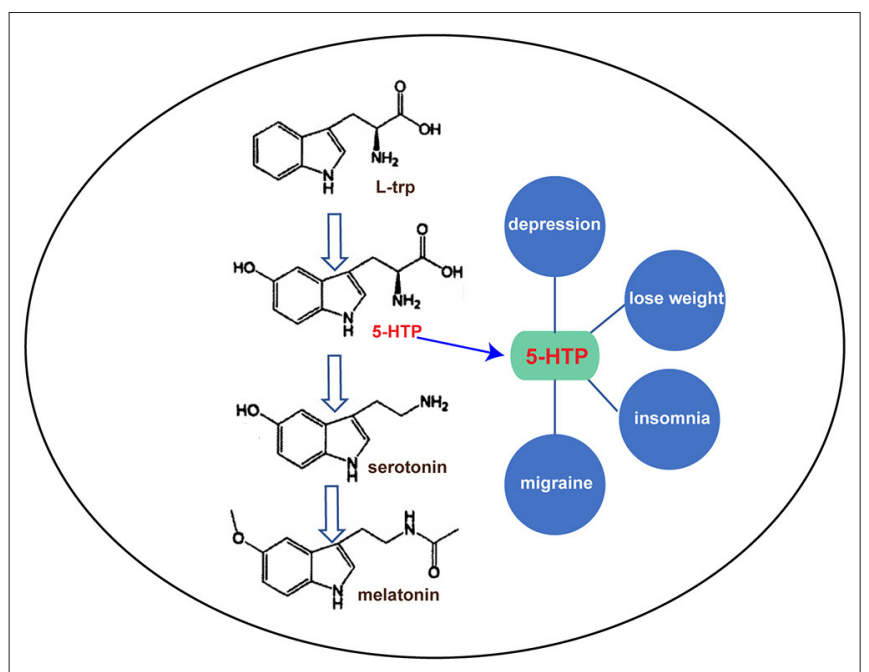

FIGURE 1 | The 5-HTP metabolic pathway and its function.

\section{PHYSIOLOGICAL FUNCTION OF 5-HTP}

As shown in Figure 1, 5-HTP has been widely studied for its important role in the treatment of depression and for weight loss. Depression is a common mental disorder with high levels of disability and stress. More than 350 million people worldwide suffer from depression, and $\sim 1$ million people commit suicide due to depression every year (World Health Organization, 2017). It has become the second most important disease worldwide, posing a serious burden on human beings. Dysfunction of serotonin in the brain is thought to be a major cause of depression. 5-HTP is a natural and safe antidepressant because it can increase serotonin levels in the brain. In a clinical trial of 107 patients with depression, $69 \%$ of symptoms improved through the daily intake of 50-300 mg of 5-HTP. The response rate to this drug was significantly faster than that of ordinary drugs (Sano, 1972). In addition, the content of 5-hydroxyindoleacetic acid (a serotonin-decomposition product) in the cerebrospinal fluid of the patients significantly increased after 5-HTP intake, indicating that 5-HTP was successfully converted to serotonin after entering the central nervous system (Takahashi et al., 1975).

Dieting leads to a sharp decrease in serotonin levels in the serum and brain, and a decrease in serotonin leads to gluttonous gluttony. 5-HTP can prevent dieting induced decrease in serotonin in patients with obesity, thus reducing appetite and assisting with weight loss (Ceci et al., 1989; Cangiano et al., 1991, 1992). In addition, 5-HTP can also improve the symptoms of fibromyalgia, including pain, morning stiffness, anxiety, and fatigue (Caruso et al., 1990; Sarzi Puttini and Caruso, 1992; Nicolodi and Sicuteri, 1996). Chronic headaches are caused by reduced serotonin levels in the body. 5-HTP has successfully been used to prevent various types of chronic headaches, including migraines, tension headaches, and adolescent headaches (Bono et al., 1982; Longo et al., 1984; Benedittis and Massei, 1985; Titus et al., 1986; De Giorgis et al., 1987; Maissen and Ludin, 1991; Nicolodi and Sicuteri, 1996). In addition, 5-HTP can increase the rapid eye movement sleep period to improve sleep quality for the treatment of insomnia.

\section{PRODUCTION OF 5-HTP}

The anabolic-metabolic engineering design for 5-HTP has gained considerable attention and has been widely studied because of its important physiological functions and huge market demand. At present, the main methods for producing 5-HTP are natural product extraction, chemical synthesis, and microbial fermentation. Among these methods, natural product extraction remains the primary method for the commercial production of 5-HTP. While microbial synthesis and catalysis provide a fast and environmentally friendly alternative to produce natural compounds of medical value.

\section{Natural Extraction of 5-HTP}

5-HTP is widely present in the seeds of legumes, with the seeds of African plant Griffonia Simplicifolia haing the highest content. The leaves and seeds of the Ghanaian tree have been used as medicine in Africa since ancient times to treat wounds, kidney disease, and for enemas. The paste made from its bark is also used to treat skin diseases, in which the main active ingredient is 5-HTP. Lemaire and Adosraku extracted 5-HTP using the alcohol method, and found that it constituted $20.83 \%$ of the fresh weight of the seeds (Lemaire and Adosraku, 2010). After optimization of the extraction temperature, the content of 5-HTP in the extract increased from 6.37 to $8.98 \%$ and the purity reached 92\% (Addotey, 2009). Using ultrafiltration membrane separation technology, the 5-HTP transfer rate was found to be $83.5 \%$, and purity reached $90.5 \%$ (Qin et al., 2014). In addition, high-purity 5-HTP was also obtained from flower beans by ultrasonic method (Duan et al., 2017).

However, the natural source of 5-HTP is relatively singular. There is a shortage of raw materials and costs are continually increasing with the increase of exploitation. The increasing market demand is impossible to meet through natural extraction alone. Therefore, there has recently been an increasing number of studies regarding the production of 5-HTP via chemical synthesis and biological fermentation.

\section{Chemical Synthesis of 5-HTP}

5-HTP is synthesized by Michael addition reaction using 5-bromoindole 3-bromo-2-hydroxyimino-propionate as the substrate. The addition reaction connects the side chain of 2-hydroxyimino-propionate to the 3-position of the indole. Subsequently, the reduction reaction, hydrolysis reaction, and resolution steps are introduced to obtain 5-HTP (Fuchun et al., 2013). In an invention patent, Raney- $\mathrm{Ni}$ and $\mathrm{ZnO}$ were added to an autoclave as catalysts. Trp, glycolic acid, and hydrochloric acid were reacted in the autoclave for $0.25-6 \mathrm{~h}$, then filtered and dried to obtain poly-hydroxy-trp drying substance. The dried substance was then reacted with trp, sodium hydroxide, and deionized water. The 5-HTP crystals were finally obtained after filtration, chromatography and cooling crystallization (Rihe, 2010). Wenhui and colleagues first demonstrated the methyl (ethyl) esterification of L-trp to form tryptophan methyl 


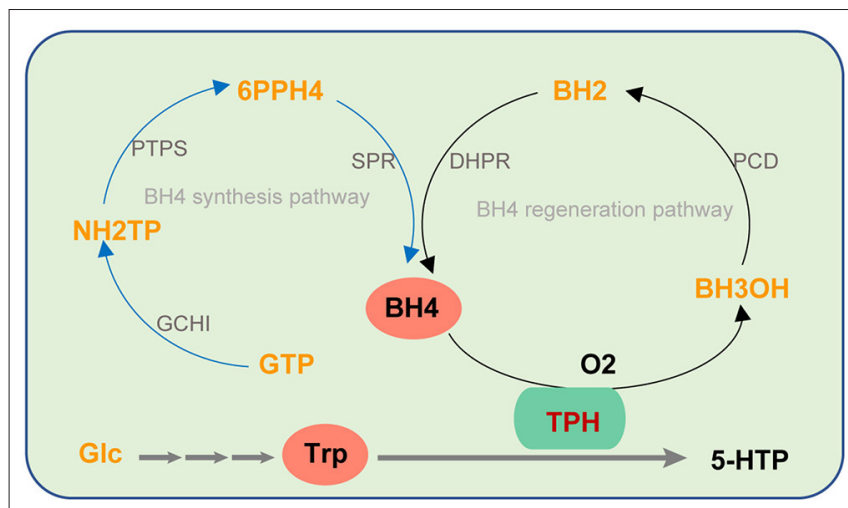

FIGURE 2 | The biosynthesis pathway of 5-HTP catalyzed by TPH using $\mathrm{BH}_{4}$ as a cofactor. The blue line represents the $\mathrm{BH}_{4}$ synthesis pathway. The black line represents $\mathrm{BH}_{4}$ regeneration pathway.

(ethyl) ester hydrochloride. 5-HTP was obtained after desalting, acetylation, redox, deacetylation, and other reactions. After cooling and crystallization, 5-HTP crystals were obtained. The purity of the product was $99.2 \%$ and the overall yield was $45 \%$ (Wenhui et al., 2013).

The chemical method for the synthesis of 5-HTP is tedious, harsh, and costly. It uses a variety of organic reagents, resulting in serious environmental pollution. Therefore, this method is not suitable for the large-scale production of 5-HTP.

\section{Biosynthesis of 5-HTP}

5-HTP production by biological methods is favored due to its advantages, such as a short production cycle, continuous production, and mild reaction conditions. In vivo, 5-HTP is obtained by L-trp hydroxylation catalyzed by trp hydroxylase (TPH) using L-trp as a substrate (Figure 2). TPH is a monooxygenase that uses trp and oxygen as substrates, and tetrahydrobiopterin $\left(\mathrm{BH}_{4}\right)$ and $\mathrm{Fe}^{2+}$ are required as cofactors in its catalytic process (Kappock and Caradonna, 1996; Fitzpatrick, 1999; Olsson et al., 2010; Roberts and Fitzpatrick, 2013).

\section{METABOLIC ENGINEERING STRATEGY FOR 5-HTP SYNTHESIS}

In vivo, 5-HTP is produced from L-trp and the reaction is catalyzed by $\mathrm{TPH}$, which uses L-trp and $\mathrm{O}_{2}$ as substrates and requires $\mathrm{BH}_{4}$ and $\mathrm{Fe}^{2+}$ as cofactors. The activity of $\mathrm{TPH}$, the supply of L-trp, and the synthesis and regeneration of $\mathrm{BH}_{4}$ are three key factors that restrict restricting 5-HTP synthesis.

\section{L-Tryptophan Hydroxylase (TPH)}

$\mathrm{TPH}$, phenylalanine hydroxylase $(\mathrm{PAH})$, and tyrosine Hydroxylase (TH) are pterin-dependent aromatic AA hydroxylases (AAAHs) (Windahl et al., 2008; Olsson et al., 2010). Moreover, these three hydroxylases have substrate interconnectedness, and each hydroxylase can catalyze the hydroxylation of these three aromatic AAs (Olsson et al., 2010; Roberts and Fitzpatrick, 2013). There are two subtypes of TPH in mammals: TPHI and TPH2 (Walther et al., 2003). TPH1 was discovered first and studied in depth. In adults, TPH1 is mainly expressed in non-nerve cells (Murphy et al., 2008). Walther et al. found that the brains of mice could still produce serotonin normally after knocking out the TPH1 gene. Further studies found another TPH, TPH2, in the brains of mice (Walther et al., 2003). TPH1 and TPH 2 have $71 \%$ AA sequence homology. $\mathrm{TPH} 2$ is mainly responsible for the synthesis of serotonin in the central nervous system, including the frontal area, thalamus, hippocampus, amygdala, and hypothalamus, whereas TPH1 is mainly expressed in the pineal gland and the gut and is responsible for the synthesis of serotonin in other parts of the body, such as the heart, lungs, and kidneys (Walther and Bader, 2003; Walther et al., 2003; Patel et al., 2004; Zhang et al., 2004; Sakowski et al., 2006).

First, TPH was heterologous expressed in E. coli, and its structure, enzymatic properties, and catalytic mechanism were studied. Windahl et al. (2008) studied the active center structure of chicken TPH1. The $\mathrm{Fe}^{2+}$ coordination structure was found to belong to the heme-independent general $\mathrm{Fe}^{2+}$ coordination structure. The $\mathrm{Fe}^{2+}$ coordination is a distorted trigonal bipyramidal coordination with His273, His278, Glu318, and an imidazole ligand. The substrate trp binds to the hydrophobic pocket of the active center. This hydrophobic pocket is composed of Tyr236, Thr266, Pro267, Glu268, Pro269, His273, Phe314, Phe319, and Lie367 (Windahl et al., 2008). McKinney et al. (2004) expressed human TPH in E. coli and yeast expression system. They found that the soluble expression of TPH could be enhanced by fusion expression with maltosebinding protein. The fusion expressed TPH's enzyme activity and affinity with L-trp was significantly improved. Moran et al. (1998) expressed rabbit-derived TPH in E. coli. It was found that the soluble expression was significantly increased after removing 101 AAs at the N-terminal and 28 AAs at the C-terminal. Interestingly, this mutated TPH exists in the form of a monomer rather than a tetramer. Kino et al. (2009) found that Leu101 and Trp180 from the active center of Pseudomonas aeruginosa $\mathrm{PAH}$ exerted effects on substrate specificity and hydroxylase activity. The enzyme catalytic rate constant, $\mathrm{K}_{\text {cat, }}$ increased 5.2 times after mutation at these two sites (Kino et al., 2009).

\section{Synthesis and Regeneration of $\mathrm{BH}_{4}$}

One difficulty in using E. coli to produce 5-HTP is that it does not synthesize the coenzyme $\mathrm{BH}_{4}$, which is essential for TPH. E. coli can synthesize analogs of $\mathrm{BH}_{4}$, tetrahydromonapterin $\left(\mathrm{MH}_{4}\right)$ (Ikemoto et al., 2002). PAH of Pseudomonas aeruginosa can use $\mathrm{MH}_{4}$ as a coenzyme to hydroxylate L-phenylalanine to L-tyrosine. Zhang et al. (2016) expressed mutant PAH or TPH in Saccharomyces cerevisiae to catalyze the production of 5-HTP from L-trp. The activities of PAH and TPH in the hydroxylation of trp with $\mathrm{MH}_{4}$ and $\mathrm{BH}_{4}$ as cofactors were compared. The results showed that the hydroxylation activity of $\mathrm{TPH}$ using $\mathrm{BH}_{4}$ as a cofactor was 17 times higher than that of $\mathrm{PAH}$ using $\mathrm{MH}_{4}$ (Zhang et al., 2016).

With an in-depth understanding of the biosynthetic pathway of $\mathrm{BH}_{4}$, Yamamoto et al. (2003) synthesized $\mathrm{BH}_{4}$ through the heterologous expression in E. coli. The synthetic pathway of 
TABLE 1 | Overview of 5-HTP production by microorganism.

\begin{tabular}{|c|c|c|c|c|}
\hline Strains & Modulations & Titer $(\mathbf{g} / \mathbf{L})$ & Cultivation & References \\
\hline E. coli & Overexpression of mutant PAH, & 0.1762 & $\begin{array}{l}\text { Shake flask; Supplementation of } \\
\mathrm{BH}_{4} \text { and } 5 \mathrm{mM} \mathrm{L-trp}\end{array}$ & $\begin{array}{l}\text { Kino et al., 2009; Hara and } \\
\text { Kino, } 2013\end{array}$ \\
\hline E. coli & $\begin{array}{l}\text { Overexpression of mutant } \mathrm{PAH} \text {; Insertion of } \mathrm{BH}_{4} \text { regeneration } \\
\text { pathway; Insertion of glucose dehydrogenase from Bacillus subtilis }\end{array}$ & 0.55 & $\begin{array}{l}\text { Shake flask; Supplementation of } \\
5 \mathrm{mM} \text { L-Trp }\end{array}$ & Hara and Kino, 2013 \\
\hline E. coli & $\begin{array}{l}\text { Mutation of PAH from Xanthomonas campestris; Co-expression of } \\
\mathrm{MH}_{4} \text { regeneration pathway and L-trp synthesis pathway }\end{array}$ & 0.1529 & $\begin{array}{l}\text { Shake flask; Supplementation } \\
\text { of glucose }\end{array}$ & Lin et al., 2014 \\
\hline E. coli & $\begin{array}{l}\text { Mutation of the PAH from Xanthomonas campestris; } \\
\text { Co-expression of } \mathrm{MH}_{4} \text { regeneration and the L-trp synthesis } \\
\text { pathway; Transformation into an L-trp high-yield strain }\end{array}$ & 0.962 & Fed-batch & $\begin{array}{l}\text { Mora-Villalobos and Zeng, } \\
2018\end{array}$ \\
\hline E. coli & $\begin{array}{l}\text { Mutation of phenylalanine-4-hydroxylases (P4Hs); Deletion of the } \\
\text { pheA, tyrA, and tnaA genes }\end{array}$ & $1.1-1.2$ & $\begin{array}{l}\text { Shake flask; Supplementation of } \\
2 \text { g/L L-Trp }\end{array}$ & Lin et al., 2014 \\
\hline E. coli & $\begin{array}{l}\text { Mutation of } \mathrm{AAAH} \text {; Insertion of the human } \mathrm{BH}_{4} \text { regeneration } \\
\text { pathway; Disruption of tryptophanase }\end{array}$ & 0.55 & Supplementation of $1 \mathrm{~g} / \mathrm{L} \mathrm{L}$-Trp & $\begin{array}{l}\text { Mora-Villalobos and Zeng, } \\
2017\end{array}$ \\
\hline E. coli & $\begin{array}{l}\text { Expression of a truncated human TPH2; Reconstitution of the } \mathrm{BH}_{4} \\
\text { synthesis and regeneration pathway; Modulation of the plasmid } \\
\text { copy number and promoter strength; Modulation of different } \\
\text { modules' expression levels }\end{array}$ & 1.3 & $\begin{array}{l}\text { Shake flask; Glycerol as } \\
\text { carbon source }\end{array}$ & Wang et al., 2018 \\
\hline E. coli & Same as the previous line & 5.1 & $\begin{array}{l}\text { Fed-batch; Glycerol as carbon } \\
\text { source }\end{array}$ & Wang et al., 2018 \\
\hline E. coli & $\begin{array}{l}\text { Expression of a truncated human TPH2; Reconstitution of the } \mathrm{BH}_{4} \\
\text { synthesis and regeneration pathway; Modulation of the plasmid } \\
\text { copy number and promoter strength; Modulation of the relative } \\
\text { expression levels among different modules; Designing promoter } \\
\text { strength to increase tryptophan production }\end{array}$ & 1.61 & $\begin{array}{l}\text { Shake flask; Glycerol as } \\
\text { carbon source }\end{array}$ & Xu et al., 2020 \\
\hline
\end{tabular}

$\mathrm{BH}_{4}$ is shown in Figure 2. The production capacity of GTP (the precursor of $\mathrm{BH}_{4}$ ) was increased by mutation breeding (Perkins et al., 1999). By optimizing the activity of GCHI (the enzyme that catalyzes the first step of $\mathrm{BH}_{4}$ biosynthesis) from different sources, $4 \mathrm{~g} / \mathrm{L} \mathrm{BH}_{4}$ was obtained under fed-batch fermentation (Yamamoto et al., 2003).

Kino et al. (2009) first expressed the mutagenic TPH in E. coli and synthesized $0.8 \mathrm{mM}$ of 5 -HTP by adding $\mathrm{BH}_{4}$ as a substrate. Subsequently, the $\mathrm{BH}_{4}$ regeneration pathway and glucose dehydrogenase from Bacillus subtilis were introduced to increase the utilization rate of $\mathrm{BH}_{4}$. The yield of 5-HTP increased to $2.5 \mathrm{mM}$ under these conditions (Table 1) (Kino et al., 2009; Hara and Kino, 2013). Knight et al. (2013) introduced the mammalian $\mathrm{BH}_{4}$ synthesis pathway and regeneration pathway into E. coli and co-expressed it with rabbit-derived TPH1. When L-trp was used as the substrate, the yield of 5-HTP reached $198 \mathrm{mg} / \mathrm{L}$ (Knight et al., 2013). Although 5-HTP synthesis was achieved by introducing the synthesis and regeneration pathway of $\mathrm{BH}_{4}$, the yield of 5-HTP was low and additional Ltrp was needed, indicating that it is not a suitable method for mass production.

\section{Optimization of trp Supply}

5-HTP yield can be increased by increasing TPH activity and introducing $\mathrm{BH}_{4}$ synthesis and regeneration pathways. Mora-Villalobos and Zeng (2017) mutated the aromatic amino acid hydroxylase of Cupriavidus taiwanensis and obtained the trp preference mutant enzyme $C_{t} \mathrm{AAAH}-$ W192F. The mutated enzyme was co-expressed with the
$\mathrm{BH}_{4}$ regeneration pathway in E. coli. Additionally, $5 \mathrm{mM}$ trp could be transformed into $2.5 \mathrm{mM}$ of 5 -HTP by shaking flask culture for $24 \mathrm{~h}$. After converting this pathway into L-trp producing bacteria, the synthesis of 5-HTP from glucose was realized. The flask yield was $100 \mathrm{mg} / \mathrm{L}$ in $60 \mathrm{~h}$, and the batch fermentation yield was $962 \mathrm{mg} / \mathrm{L}$ (Mora-Villalobos and Zeng, 2018).

Wang et al. (2018) introduced human TPH into E. coli BL21, and co-expressed it with the synthetic and regenerative pathways of human $\mathrm{BH}_{4}$. The engineered bacteria hydroxylated $2 \mathrm{~g} / \mathrm{L}$ trp to produce $1.24 \mathrm{~g} / \mathrm{L} 5$-HTP. The authors further introduced the trp synthesis pathway into the recombinant E. coli to realize the biosynthesis of 5-HTP. After the optimization of culture conditions, the yield of 5-HTP was further increased by 13 times to $314.8 \mathrm{mg} / \mathrm{L}$. After module optimization, which included: (a)enzymatic modification to improve the hydroxylation activity of TPH, (b)reduction of the copy number of the trp synthesis gene, and (c) regulation of the promoter strength of genes involved in $\mathrm{BH}_{4}$ synthesis and regeneration, the yield of 5-HTP in the modified recombinant strain HTPL01-LMT was $1.29 \mathrm{~g} / \mathrm{L}$, 3.1-fold increase (Wang et al., 2018). To improve the stability of this system, the authors further integrated the L-trp biosynthesis pathway into E. coli genome and designed the promoter strength of the enzyme-coding gene, which catalyzes the first step of Ltrp biosynthesis. To regulate the production of 5-HTP, they also regulated the copy number of the L-TPH coding gene plasmid. After these optimization steps, the amount of 5-HTP of shake flask fermentation increased to $1.61 \mathrm{~g} / \mathrm{ml}$, which was $24 \%$ higher than that of the original strain (Table 1) (Xu et al., 2020). 


\section{PROSPECTS}

This review assesses the synthesis and research progress of 5HTP. Compared with natural product extraction and chemical synthesis, biosynthesis has the advantages of a short cycle, continuous production and mild reaction conditions; thus, it has garnered considerable research attention. In the biosynthesis process, three aspects of optimization have been implemented to increase the output of 5-HTP; (a) improving the hydroxylation activity of the TPH enzyme by directed evolution, (b) introducing $\mathrm{BH}_{4}$ synthesis and the regeneration pathway, (c) introducing the trp synthesis pathway. To date, the yield of shake flask culture has reached $1.61 \mathrm{~g} / \mathrm{L}$.

Although 5-HTP production has increased 10-fold, remains insufficient for large-scale commercial production. The metabolic network is a complex system, and the efficiency of the target metabolic pathway is often affected by other metabolic pathways. Therefore, strain evolution and breeding for global metabolism may effectively improve the yield of the target product. Besides, high-density cell culture is another strategy for increasing the yield. Combined with the optimization of fermentation conditions and the improvement of cell culture density, the yield of 5-HTP could be further improved.

\section{REFERENCES}

Addotey, J. (2009). Local production of 5-HTP from the seeds of Griffonia simplicifolia. World J. Pharm. Pharm. 5.

Benedittis, G. D., and Massei, R. (1985). Serotonin precursors in chronic primary headache. A double-blind cross-over study with L-5-hydroxytryptophan vs. placebo. J. Neurosurg. Sci. 29, 239-248.

Birdsall, T. C. (1998). 5-Hydroxytryptophan: a clinically-effective serotonin precursor. Altern. Med. Rev. 3, 271-280.

Bono, G., Criscuoli, M., Martignoni, E., Salmon, S., and Nappi, G. (1982). Serotonin precursors in migraine prophylaxis. Adv. Neurol. 33:357.

Cangiano, C., Ceci, F., Cairella, M., Cascino, A., Ben, M. D., Laviano, A., et al. (1991). Effects of 5-Hydroxytryptophan on Eating Behavior and Adherence to Dietary Prescriptions in Obese Adult Subjects. New York, NY: Springer. doi: 10.1007/978-1-4684-5952-4_73

Cangiano, C., Ceci, F., Cascino, A., Del Ben, M., Laviano, A., Muscaritoli, M., et al. (1992). Eating behavior and adherence to dietary prescriptions in obese adult subjects treated with 5-hydroxytryptophan. Am. J. Clin. Nutr. 56, 863-867. doi: $10.1093 /$ ajcn/56.5.863

Caruso, I., Sarzi Puttini, P., Cazzola, M., and Azzolini, V. (1990). Doubleblind study of 5-hydroxytryptophan versus placebo in the treatment of primary fibromyalgia syndrome. J. Int. Med. Res. 18, 201-209. doi: $10.1177 / 030006059001800304$

Ceci, F., Cangiano, C., Cairella, M., Cascino, A., Del Ben, M., Muscaritoli, M., et al. (1989). The effects of oral 5-hydroxytryptophan administration on feeding behavior in obese adult female subjects. J. Neural Transm. 76, 109-117. doi: 10.1007/BF01578751

De Giorgis, G., Miletto, R., Iannuccelli, M., Camuffo, M., and Scerni, S. (1987). Headache in association with sleep disorders in children: a psychodiagnostic evaluation and controlled clinical study-L-5-HTP versus placebo. Drugs Exp. Clin. Res 13:425.

Duan, G., Mingbo, G., Qiao, C., Xiaochen, W., and Yining, L. (2017). Ultrasonic extraction of 5-hydroxytryptophan from adzuki bean. Guangzhou Chem. Indus. $45,52-54$.

Fitzpatrick, P. F. (1999). Tetrahydropterin-dependent amino acid hydroxylases. Annu. Rev. Biochem. 68, 355-381. doi: 10.1146/annurev.biochem.68.1.355
AUTHOR CONTRIBUTIONS

$\mathrm{X}$-XL wrote the manuscript. BZ and L-ZA revised the Metabolic engineering strategy for 5-HTP synthesis section. All the authors contributed to the literature collection and data analysis, and approved it for publication.

\section{FUNDING}

This work was sponsored by the Shanghai Sailing Program (20YF1433500); the National Key R\&D Program of China [Grant No. 2018YFC1604305]; the Shanghai Agriculture Applied Technology Development Program, China [Grant No. 2019-02-08-00-07-F01152]; the Natural Science Foundation of China [Grant No. 31871757]. Shanghai Technical Standard Program, China [18DZ2200200]; Shanghai Engineering Research Center of food microbiology program [19DZ22 81100].

\section{ACKNOWLEDGMENTS}

We would like to thank Editage (www.editage.cn) for English language editing.

Fuchun, G., Can, L., and Yan, X. (2013). A New Simple Method for Synthesis of L-5-hydroxytryptophan, CN. Patent CN103554005A.

Hara, R., and Kino, K. (2013). Enhanced synthesis of 5-hydroxy-ltryptophan through tetrahydropterin regeneration. AMB Express 3:70. doi: 10.1186/2191-0855-3-70

Ikemoto, K., Sugimoto, T., Murata, S., Tazawa, M., Nomura, T., Ichinose, H., et al. (2002). (6R)-5,6,7,8-tetrahydro-L-monapterin from Escherichia coli, a novel natural unconjugated tetrahydropterin. Biol. Chem. 383, 325-330. doi: 10.1515/BC.2002.035

JunDe, L., Shaohua, L., and Mi, T. (2014). Research progress of 5-hydroxytryptophan. Fine Specialized Chem. 22, 36-39.

Kappock, T. J., and Caradonna, J. P. (1996). Pterin-dependent amino acid hydroxylases. Chem. Rev. 96, 2659-2756. doi: 10.1021/cr9402034

Kino, K., Hara, R., and Nozawa, A. (2009). Enhancement of L-tryptophan 5hydroxylation activity by structure-based modification of L-phenylalanine 4hydroxylase from Chromobacterium violaceum. J. Biosci. Bioeng. 108, 184-189. doi: 10.1016/j.jbiosc.2009.04.002

Knight, E. M., Zhu, J., Förster, J., and Hao, L. (2013). Microorganisms for the production of 5-hydroxytryptophan. Nippon Hinyokika Gakkai Zasshi the Japanese J. Urol. 56, 317-330. doi: 10.1093/mnras/stt2484

Lemaire, P. A., and Adosraku, R. K. (2010). An HPLC method for the direct assay of the serotonin precursor, 5-hydroxytrophan, in seeds of Griffonia simplicifolia. Phytochem. Anal. 13, 333-337. doi: 10.1002/pca.659

Lin, Y., Sun, X., Yuan, Q., and Yan, Y. (2014). Engineering bacterial phenylalanine 4-hydroxylase for microbial synthesis of human neurotransmitter precursor 5-hydroxytryptophan. ACS Synth. Biol. 3, 497-505. doi: 10.1021/sb5002505

Longo, G., Rudoi, I., Iannuccelli, M., Strinati, R., and Panizon, F. (1984). Treatment of essential headache in developmental age with L-5-HTP (cross over doubleblind study versus placebo). Pediatr. Med. Chir. 6, 241-245.

Maissen, C. P., and Ludin, H. P. (1991). Comparison of the effect of 5hydroxytryptophan and propranolol in the interval treatment of migraine. Schwzerische Medizinische Wochenschrift 121, 1585-1590.

McKinney, J., Knappskog, P. M., Pereira, J., Ekern, T., Toska, K., Kuitert, B. B., et al. (2004). Expression and purification of human tryptophan hydroxylase from Escherichia coli and Pichia pastoris. Protein Expr. Purif. 33, 185-194. doi: 10.1016/j.pep.2003.09.014 
Moran, G. R., Daubner, S. C., and Fitzpatrick, P. F. (1998). Expression and characterization of the catalytic core of tryptophan hydroxylase. J. Biol. Chem. 273, 12259-12266. doi: 10.1074/jbc.273.20.12259

Mora-Villalobos, J.-A., and Zeng, A. P. (2017). Protein and pathway engineering for the biosynthesis of 5-hydroxytryptophan in Escherichia coli. Eng. Life Sci. 17, 892-899. doi: 10.1002/elsc.201700064

Mora-Villalobos, J. A., and Zeng, A. P. (2018). Synthetic pathways and processes for effective production of 5-hydroxytryptophan and serotonin from glucose in Escherichia coli. J. Biol. Eng. 12:3. doi: 10.1186/s13036-018-0094-7

Murphy, K. L., Zhang, X., Gainetdinov, R. R., Beaulieu, J. M., and Caron, M. G. (2008). A regulatory domain in the $\mathrm{n}$ terminus of tryptophan hydroxylase 2 controls enzyme expression. J. Biol. Chem. 283, 13216-13224. doi: 10.1074/jbc.M706749200

Nicolodi, M., and Sicuteri, F. (1996). Fibromyalgia and migraine, two faces of the same mechanism. Serotonin as the common clue for pathogenesis and therapy. Adv. Exp. Med. Biol. 398, 373-379. doi: 10.1007/978-1-4613-0381-7_58

Olsson, E., Teigen, K., Martinez, A., and Jensen, V. R. (2010). The aromatic amino acid hydroxylase mechanism: a perspective from computational chemistry. Adv. Inorg. Chem. 62, 437-500. doi: 10.1016/S0898-8838(10)62011-9

Patel, P. D., Pontrello, C., and Burke, S. (2004). Robust and tissue-specific expression of TPH2 versus TPH1 in rat raphe and pineal gland. Biol. Psychiatry 55, 428-433. doi: 10.1016/j.biopsych.2003.09.002

Perkins, J. B., Sloma, A., Hermann, T., Theriault, K., Zachgo, E., Erdenberger, T., et al. (1999). Genetic engineering of Bacillus subtilis for the commercial production of riboflavin. J. Indus. Microbiol. Biotechnol. 22, 8-18. doi: $10.1038 /$ sj.jim.2900587

Qin, Z., Xuesong, H., Ling, Q., and Yanjie, K. (2014). Study on separation and purification of 5-hydroxytryptophan from Ghanaian seeds by ultrafiltration membrane. Res. Dev. Nat. Products 26, 2033-2036.

Rihe, S. (2010). Synthesis of L-5-Hydroxytryptophan. Patent CN101323586B.

Roberts, K. M., and Fitzpatrick, P. F. (2013). Mechanisms of tryptophan and tyrosine hydroxylase. IUBMB Life 65, 350-357. doi: 10.1002/iub.1144

Sakowski, S. A., Geddes, T. J., Thomas, D. M., Levi, E., Hatfield, J. S., and Kuhn, D. M. (2006). Differential tissue distribution of tryptophan hydroxylase isoforms 1 and 2 as revealed with monospecific antibodies. Brain Res. 1085, 11-18. doi: 10.1016/j.brainres.2006.02.047

Sano, I. (1972). L-5-hydroxytryptophan(L-5-HTP) therapy in endogenous depression. Munch. Med. Wochenschr. 114, 1713-1716. doi: 10.1111/j.1440-1819.1972.tb01107.x

Sarzi Puttini, P., and Caruso, I. (1992). Primary fibromyalgia syndrome and 5hydroxy-L-tryptophan: a 90-day open study. J. Int. Med. Res. 20, 182-189. doi: $10.1177 / 030006059202000210$

Takahashi, S., Kondo, H., and Kato, N. (1975). Effect of 1-5-hydroxytryptophan on brain monoamine metabolism and evaluation of its clinical effect in depressed patients. J. Psychiatr. Res. 12, 177-187. doi: 10.1016/0022-3956(75)90025-4
Titus, F., Dávalos, A., Alom, J., and Codina, A. (1986). 5-Hydroxytryptophan versus methysergide in the prophylaxis of migraine. Randomized clinical trial. Eur. Neurol. 25, 327-329. doi: 10.1159/000116030

Walther, D. J., and Bader, M. (2003). A unique central tryptophan hydroxylase isoform. Biochem. Pharmacol. 66, 1673-1680. doi: 10.1016/S0006-2952(03)00556-2

Walther, D. J., Peter, J. U., Bashammakh, S., Hörtnagl, H., Voits, M., Fink, H., et al. (2003). Synthesis of serotonin by a second tryptophan hydroxylase isoform. Science 299:76. doi: 10.1126/science. 1078197

Wang, H., Liu, W., Shi, F., Huang, L., Lian, J., Qu, L., et al. (2018). Metabolic pathway engineering for high-level production of 5-hydroxytryptophan in Escherichia coli. Metab. Eng. 48, 279-287. doi: 10.1016/j.ymben.2018.06.007

Wenhui, H., Xing, T., Xiaobing, L., and Jiajin, Y. (2013). A Method for Preparing L5-Hydroxytryptophan. Patent CN201110272240.3.

Windahl, M. S., Petersen, C. R., Christensen, H. E., and Harris, P. (2008). Crystal structure of tryptophan hydroxylase with bound amino acid substrate. Biochemistry 47, 12087-12094. doi: 10.1021/bi8015263

World Health Organization (2017). Depression and Other Common Mental Disorders: Global Health Estimates. Geneva: World Health Organization.

Xu, D., Fang, M., Wang, H., Huang, L., Xu, Q., and Xu, Z. (2020). Enhanced production of 5-hydroxytryptophan through the regulation of Ltryptophan biosynthetic pathway. Appl. Microbiol. Biotechnol. 104, 2481-2488. doi: 10.1007/s00253-020-10371-y

Yamamoto, K., Kataoka, E., Miyamoto, N., Furukawa, K., Ohsuye, K., and Yabuta, M. (2003). Genetic engineering of Escherichia coli for production of tetrahydrobiopterin. Metab. Eng. 5, 246-254. doi: 10.1016/S1096-7176(03)00046-6

Zhang, J., Wu, C., Sheng, J., and Feng, X. (2016). Molecular basis of 5hydroxytryptophan synthesis in Saccharomyces cerevisiae. Mol. Biosyst. 12, 1432-1435. doi: 10.1039/C5MB00888C

Zhang, X., Beaulieu, J. M., Sotnikova, T. D., Gainetdinov, R. R., and Caron, M. G. (2004). Tryptophan hydroxylase-2 controls brain serotonin synthesis. Science 305:217. doi: 10.1126/science. 1097540

Conflict of Interest: The authors declare that the research was conducted in the absence of any commercial or financial relationships that could be construed as a potential conflict of interest.

Copyright (c) $2021 \mathrm{Liu}$, Zhang and Ai. This is an open-access article distributed under the terms of the Creative Commons Attribution License (CC BY). The use, distribution or reproduction in other forums is permitted, provided the original author(s) and the copyright owner(s) are credited and that the original publication in this journal is cited, in accordance with accepted academic practice. No use, distribution or reproduction is permitted which does not comply with these terms. 